\title{
Deweyan Progressive Education within Ontario Elementary Health and Physical Education
}

\author{
Daniel T. Ryan ${ }^{1}$, Thomas G. Ryan ${ }^{2}$
}

\begin{abstract}
The objective is to explore Deweyan Progressive Education within Ontario Health and Physical Education. The need to review this area was instigated within the last two years as the Ontario provincial government in Canada has implemented new 2019 Ontario Health and Physical Education curricular guide which contains significant modernizations. The document established a concern for mental health development, online safety, bullying prevention, road safety, substance abuse, concussions, and healthy body image within the 250-page document. The authors undertook a latent content analysis revealing a challenge to compress this curricular content into Health and Physical Education classes that are infrequently scheduled. Teachers, it is understood, will learn that students need progressive instruction and constructive feedback as they practise, reflect, and learn experientially in a safe environment. This review supports educators as they work to better understand the term progressive education and its current pertinence.
\end{abstract}

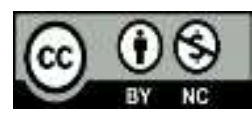

Keywords: Dewey, philosophy, progressivism, health instruction, physical education

\section{Introduction}

Progressive teaching is a centrepiece of this 2019 Ontario Ministry of Education document. Certainly "no education is progressive, unless it is making progress" (Cremin, 1959, p. 171). Progressive education is distinct and understood as learner participation to the extent that students direct the learning process (Noddings, 1995). Progressivism, as a philosophy of education, is one of the most "enduring educational reform movements in the history of North America" (Davies, 2002, p. 269). Labaree (2005) suggests progressive education involves meeting learner needs and addressing interests within a progressive phase of learning.

The progressive stance is linked to student learning in key segments and has manifested itself into grade levelling (stratification) today (Ryan, 2008b).

\footnotetext{
${ }^{1}$ Graduate Student, Nipissing University, North Bay Ontario, Canada Email: dan-ryan@outlook.com

${ }^{2}$ Professor, Faculty of Education, Graduate Studies, Nipissing University, North Bay Ontario, Canada, Email: thomasr@,nipissingu.ca
} 
Progressivism involves skills instruction used within any subject, instead of focussed recall of a particular individual subject (rote memory). Admittedly, learning is more appealing, valuable and indelible to the student when they acquire progressive and practical (authentic) skills and not just memories of facts (Ryan et al., 2018).

In addition, progressive education stimulates discovery and encourages student self-directed learning through active engagement (Ryan, 2008b). Similarly, the Ontario elementary health and physical education curriculum is centred upon developing and refining students' knowledge and skills associated with strategic overall expectations. "This approach reflects and accommodates the progressive nature of skill development in health and physical education" (Ontario Ministry of Education, 2019, p.21). Reading this excerpt requires an understanding of progressive education, enacted by “...having students work on projects that express student purposes and that integrate the disciplines around socially relevant themes, promoting values of community, cooperation, tolerance, justice and democratic equality" (Labaree, 2005, p. 277).

\section{Research Methodology}

Latent content analysis (Kindermann, 2020) is a research mode for the "subjective interpretation of the content of text data" (Hsieh \& Shannon, 2005, p.1280). Such text as found within a curriculum document lends itself to content analysis. This systematic and strategic review mode illuminates word usage frequencies and offer insights and positions that authenticate associations and findings (Kindermann, 2020). Certain key terms and words were first identified, then highlighted, yielding frequencies for each term (Schreier, 2012). For instance, the word progressive was found 12 times and the word authentic 18 times within the 320-page curriculum document. If a relevant word surfaced often (ten times or more) it was labelled significant and guided the latent content analysis. The recursive reading of the text created frames of reference and links with extant literature (Bowen, 2009), that were expanded upon as follows herein.

\subsection{Philosophy of Progressive Education}

Progressive education complements the political philosophy of progressive liberalism as each situates humankind optimistically (Bowers, 1967). Progressive educators' belive in the value of individualism which separates itself from a traditional education (Ryan, 2008a). Memory work was abandoned as learners were taught to organize and to draw meaning from their own experiences. The importance of experience is also emphasized in the 2019 curriculum which suggests that "differences in life experiences and exposure to opportunities, can affect development, and that developmental events are not specifically age-dependent" (Ontario Ministry of Education, 2019, p.21). Even 
though Dewey was the founder of progressivism, he was critical of total freedom of students and the diminishing role of the teacher. Nonetheless, progressivism has transformed the educational landscape (Reese, 2001), as many educators today enact some aspect of progressivism (Ryan, 2008a).

\subsection{Culture}

Culture appears 45 times on 32 pages of the new curriculum and is a fundamental concern in Dewey's philosophy via the transmission of cultural values and norms. Educators need be aware that a culture is infused with enduring beliefs that often shape youth experiences. The experiences instigate values which are tangible and significant for them. Hence, progressive education prepares students for democratic life by ensuring the learning is relevant to their current stage of life (Noddings, 1995). To make learning relevant, Dewey argued for less rigidity in curriculum thereby allowing for discipline crossover. For example, a math class could include art and language (literacy) should be cross curricular (Noddings, 1995). The Ontario elementary Health \& Physical Education (2019) endorses interdisciplinary study suggesting, "students learn that they can apply the skills they acquire in one subject to various other contexts and subjects" (p.13). Progressive education would have the curriculum unified for cross-curricular freedom. For example, students can apply problem-solving skills in math,

as they learn new skills in health and physical education, and they can apply various other critical and creative thinking processes that they develop in health and physical education to their study of dance, or to question historical interpretations, or to make connections between personal actions and environmental impacts" (Ontario Ministry of Education, 2019, p.13)

\subsection{Darwin and Dewey}

Noddings (1995) observes the influence of Darwin on Dewey, with references to evolution and humans as active intelligent organisms. Dewey adopted Darwin's naturalistic outlook towards humanity, and this is seen in the explanation of humans as social animals. People are communicators, and this need to provide the stimulus for common values. The Ontario Health and Physical Education (2019) curriculum promotes "important educational values that support the development of character. These include striving to achieve one's personal best, equity and fair play, respect for diversity, sensitivity and respect for individual requirements and needs, and good health and well-being" (Ontario Ministry of Education, 2019, p.8). Dewey was also most concerned with a person's common biological condition or well-being. 
Admittedly each of us need the essentials to survive, we want to protect family, and build healthy relationships with others. In the school setting it is "therefore important for schools and parents to work together to ensure that home and school provide a mutually supportive framework for young people's education" (Ontario Ministry of Education, 2019, p.14). Dewey's stance and beliefs were influenced by others just as the current Ontario Health and Physical Education (2019) demonstrates its influences via positions, values, and stances within the current curricular text. Dewey was influenced, and fond of Darwin, especially his best-known work, The Evolution of Species (Noddings, 1995). The evolutionary human element had a large effect on Dewey, and Darwinism is important to keep in mind when reading his work, especially his philosophy of progressive education (Ryan, 2008b).

\subsection{Plato and Dewey}

Philosophy of education was also a philosophy of life for Dewey (Noddings, 1995). "Plato once defined a slave as the person who executes the purposes of another, and ... a person is also a slave who is enslaved to his own blind desires" (Noddings, 1995, p. 25). The function of progressive education rejects the traditional and severely restrictive formal education idea that students must be prescribed and memorize course content to create learning. Rather, the student is a free person and a free thinker as well and deserve to right to participate in their own learning as opposed to being told what to learn (Noddings, 1995). Similarly, Ontario Health and Physical Education (2019) value student "development of critical and creative thinking skills, [as students] . . . increase their capacity to make connections with the world around them" (p.73). Students "learn to question, interpret, predict, analyse, synthesize, detect bias, and distinguish between alternatives" (Ontario Ministry of Education, 2019, p.28), which may lead to a free-thinking person.

To characterize democracy is to describe much of the philosophy of progressive education (Ryan, 2008a). Dewey saw Progressive Education as an extension of democracy and the classroom as an effective place to establish democratic life, working on problems, making rules, testing, evaluating, and debating ideas. All of which, serve to produce students that can make the transition more easily into adult democratic life (Noddings, 1995). Noddings also was an advocate for problem-based learning involving work on common, relevant problems socially. Through this process, students as inquirers improve their own learning, as well as learning about their classmates. Indeed, students need to "apply critical thinking and problem-solving strategies and to address issues through group discussions, role play, case study analysis, and other means, they can help them develop and practise the skills they need for building healthy 
relationships" (Ontario Ministry of Education, 2019, p.74), within present day classes and in the future beyond school.

\subsection{Rousseau and Dewey}

Progressive education was not without critics, yet Rousseau and Dewey were similar in that they both viewed the best form of education to be a childcentered approach. Both saw timing in education to be an important part of the educational journey. Nevertheless, unlike Rousseau, Dewey thought children were not born good or bad, instead he believed that children are born with potential. Dewey insisted the greatest influence on children in the classroom is the environment (Noddings, 1995, p. 30). Similarly, the Ontario elementary Health \& Physical Education (2019) curricular document claims,

with a broader awareness of mental health, educators can plan instructional strategies that contribute to a supportive classroom climate for learning in all subject areas, build awareness of mental health, and reduce stigma associated with mental illness. Taking students' wellbeing, including their mental health, into account when planning instructional approaches helps establish a strong foundation for learning. (Ontario Ministry of Education, 2019, p.5)

Indeed, educators who bring "enthusiasm and varied teaching and assessment approaches to the classroom, addressing individual students' needs and ensuring sound learning opportunities for every student" (Ontario Ministry of Education, 2019, p.15). Another major difference between Rousseau and Dewey was Dewey's allegiance to democracy and good citizenship contrasting Rousseau's belief that, "individuals had to give up or drastically adapt their natural goodness in order to be useful citizens, Dewey insisted that state and individual are, ideally, in a relation of mutual support" (Noddings, 1995, p. 30).

\subsection{Herbart and Dewey}

Philosopher Johann Freidrich Herbart believed information is provided that incites a memory or experience for the student to facilitate and motivate the rest of the learning process. He is credited with supplying a structured and scientific view of teaching and instructing. Dewey was appreciative of Herbart's effort to bring, "the work of teaching out of the region of routine and accident" (Noddings, 1995, p. 20). Still, Herbart asked questions that are useful in the science of teaching. The greatest mistake in his theory was his disregard of the naturalistic human as a living organism and its purposes. Teaching was not as formulaic and mechanical as Herbart proposed. Not all subjects, teachers, or students can follow the same steps and achieve the same results. Teaching, and education as a whole is a creative human endeavor, and an unyielding process ignores this. This is echoed in the 2019 Ontario Ministry of Education document 
as it states: "Learning in health and physical education should be directly connected to the needs and abilities of individual students" (p. 9), and "frameworks recognize that individual differences, as well as differences in life experiences and exposure to opportunities, can affect development, and that developmental events are not specifically age-dependent" (Ontario Ministry of Education, 2019, p.4). Ontario teachers are free to assess and meet the needs of students in any approved creative manner they see fit within the school, community and classroom.

\subsection{Hegel and Dewey}

Among one of Dewey's greatest influences is Georg Wilhelm Friedrich Hegel. Hegel believed, "only the mind is real and that human thought, through participation in the universal spirit, progresses toward a preordained ideal by a dialectical process of resolving opposites through synthesis" (Noddings, 1995, p. 22). Although Dewey did not follow Hegel's philosophy in its entirety, he was a frequent user of his dialectical method. Incidentally, located in the new 2019 Ontario Elementary Health \& Physical Education curriculum is the belief that, the expectations in all strands give students a chance to engage in brainstorming, reporting, and other oral activities to identify what they know about a new topic, discuss strategies for solving a problem, present and defend ideas or debate issues, and offer critiques or feedback on work, skill demonstrations, or opinions expressed by their peers. (Ontario Ministry of Education, 2019, p.79)

The idea that all students will present and defend their ideas and/or debate is a clear embracement of Hegel and the dialectical process as this "cognitive conflict is the catalyst that stimulates the creation of new knowledge" (Woods, 2012, p. 134). Students in classrooms are invited to "offer critiques or feedback on work, skill demonstrations, or opinions expressed by their peers" (Ontario Ministry of Education, 2019, p. 79), which sets up dialectical experiences and/or moments.

Noddings believes Dewey frequently poses two extremes, for example, "in Experience and Education," Dewey contrasts the "old" education with the "new," but he does not unequivocally endorse the new" (Noddings, 1995, p. 23). Dewey used the dialectical method to help build his philosophy by highlighting the good and bad of both old and new education to empower his own philosophy of progressive education. Nonetheless, he was quick to let his contemporaries know that this process was nothing new and gives Hegel his credit as a major influence.

\subsection{Pragmatic Naturalism}

Since Dewey and progressivism assume a liberal and naturalistic stance, Dewey is frequently labelled a pragmatist, although, like himself, Charles 
Sanders Peirce, William James, and George Herbert Mead, are often labelled pragmatists. Dewey had difficulty with the label because it was regularly used in a negative and critical manner (Noddings, 1995). Dewey favoured the term naturalism and Deweyan authors tried to replace pragmatist with synonymous words like instrumentalism or experimentalism (Ryan, 2008b). Both have pejorative connotations, therefore the solution in recent times has been to refer to Dewey and his philosophy as pragmatic naturalism (Noddings, 1995).

Another figure closely aligned with Dewey's philosophy is Jean Piaget who detailed stages in child development. However, as a constructivist, Piaget pointed to his scientific cognitive evidence to support his claims for each stage in a child's development (Ryan et al., 2018). Dewey's naturalism prevented him from following Piaget's thinking and was continually wary of "unobservable traits to account for student behaviour and development" (Noddings, 1995, p. 23). If Dewey were alive today, he may be persuaded to agree more with Piaget given the additional research that demonstrates behaviour linked to brain development akin to the "machine program" of a computer (p. 23).

The terminology involved in Dewey's theory of education is also of much debate. R.S Peters questions Dewey's use of the terms "purpose" and "aim" interchangeably. Purpose is used in relation to action and "aim" refers to a target requiring attention in order to be successful (Noddings, 1995, p. 25). So, Dewey should only talk about the "aims" of education and not the "purpose" in communicating his philosophy (p. 25). With linguistic uncertainty out of the way, Dewey asserted that teachers must have aims for pedagogical tasks the same way their students must have objectives in their own learning goals. From this, Noddings explains the greatest distinction to be made between progressive and traditional education is progressivism's aim to "secure the active cooperation of the pupil in the purposes involved in studying" (Noddings, 1995, p. 25).

The main goal or "aim" of education for Dewey is more education (Noddings, 1995, p. 25). Therefore, education to Dewey is not just a means to an end, but a means to a means. So long as educators inspire their students to pursue more education, they have done their job correctly. This need to inspire is detailed in the Ontario Elementary Health \& Physical Education which states: "Every student is supported and inspired to succeed in a culture of high expectations for learning" (Ontario Ministry of Education, 2019, p. 79). This is important because student or teacher failure to identify an aim and/or purpose in their education actually demonstrates that the education itself has failed according to Dewey. In current Ontario curriculum aims are often embedded in policy which is meant "to maintain high standards, improve student learning, and 
benefit students, parents, and teachers in elementary and secondary schools across the province" (Ontario Ministry of Education, 2019, p.45).

\subsection{Opposition}

There is, and always has been, opposition to Dewey and the philosophy of progressive education since there is a vagueness within Dewey's examples and his descriptions of his most basic concepts (Noddings, 1995). Noddings asks: "Can we really talk meaningfully about growth without specifying its direction? What exactly is the "experience" that Dewey sometimes identifies with personal meaning and sometimes with culture? (p. 32). Pedagogical critics point out that he did not pay enough attention to the social factors in the classroom that are increasingly relevant today, such as, identity, economic status, and ability. In the current 2019 Ontario Elementary Health \& Physical Education curricula educators are told: "A well-rounded educational experience prioritizes socialemotional learning, physical and mental health, and inclusion together with academic success for all students" (Ontario Ministry of Education, 2019, p.3). Therefore, the Ontario educator may elect to be a progressive educator and while observing the provincial curricula any vagueness in the philosophy of progressivism is erased, for instance the 2019 curricula prompt educators to remember that a person is more than just student; they are a member of society who has, a variety of factors, known as the determinants of health, [that] have been shown to affect a person's overall state of well-being. Some of these are income and social status, education and literacy, gender, culture, physical environments, social supports and coping skills, and access to health services (Ontario Ministry of Education, 2019, p.4). It is quite helpful for classroom educators to have a current curriculum that is both progressive and modern to supplement Dewey's philosophy of education.

However, Dewey did not offer any solutions for educators to handle conflicts surrounding these same social factors including race conflicts, group politics, first-language differences, and economic disparity between students (Noddings, 1995, p. 32). Critics also suggest he put too much faith in the power of scientific thought to be foolproof solutions to any problems the education system could encounter. Noddings believes much of his oversight is due to focusing too much on transforming the classroom into a democracy instead of considering the problems that impact democracy itself. Thus, these problems involved in democracy will more often than not occur in a democratic classroom. Therefore, in Dewey's philosophy of progressive education he advises, "handling race conflicts, pressure-group politics, growing gaps between rich and poor, and the unhappy possibility that science might aggravate rather than ameliorate our problems" (p. 32) is detailed. Again, Dewey's fixation on democracy limits the 
solutions that can be found in his work. Unfortunately, they depend on an almost ideal circumstances within a democracy to be realized. In other words, the opposition's view of Dewey's progressive education is his naivety considering the "inherit power dynamics and struggles that exist as a part of the everyday human experience within a democracy and the utopian conditions required for it to function optimally" (p.32).

\subsection{Progressive Present-day Pedagogy \\ Project based learning (PBL)}

"The world is moving at a tremendous rate - no one knows where. We must prepare our children not for the world of the past - not for our world - but, for their world - the world of the future" (Little, 2013, p. 85). Progressive education in the present is now infused with technological innovation to access possibilities. Problem-based learning (PBL) is rooted in Ontario (Canada) (Barrows \& Tamblyn, 1976, 1980), and is currently a preferred instructional mode in health education globally. The ". . p primary goal of PBL is to enhance students' application of knowledge, problem solving and self-directed learning skill by requiring them to actively articulate, understand and solve problems" (Jonassen \& Hung, 2008, p. 15). Many of these technologies infuse projects and begin with a set of inquiry-based questions. These questions, supply students with purpose for their learning and exploration to a solution. "Dewey wanted students to puzzle over human events and activities. Why might these people have become athletes? What else influenced the development of sport? What have ocean currents and winds to do with the activities of human beings?" (Noddings, 1995). Demirel and Dağyar's (2016) meta-analysis of 48 PBL investigations determined PBL positively influences student attitudes which heighten engagement. "PBL has been found to be superior when it comes to long-term retention, skill development, and satisfaction of students and teachers" (Korpi et al., 2019, p. 2).

This rapidly developing field falls under the umbrella term, STEM or science, technology, engineering, and mathematics (Little, 2012). Traditionally, the disciplines were taught separately. However, with the advent of technology, PBL, and the need for tech skills in the modern workplace, these subjects are taught and learned in conjunction to learn new in-demand skills such as coding, web design, and computer programming. In order for these skills to be learned, students must incorporate knowledge from all of the subjects comprised of STEM (Western Australia Department of Education, 2021). Progressive educators are concerned with the needs of learners and the landscape of work as they lead his innovative learning model (Little, 2012, p. 95). 


\subsection{Gamification}

Game appears over 100 times on 81 pages of the new curriculum. A game is a "system in which players engage in artificial conflict characterized by rules that result in a quantifiable outcome" (Salen \& Zimmerman, 2004 p.80). To gamify,

educational contexts, [it] must be tangible for the students (avatars, points, levels, achievements, insignia), they must create a sense of action and progression (rules, challenges, competition, cooperation, feedback) and they must regulate the group's social-emotional competencies (motivations, emotions, obligations, social relationships) and, consequently, modulate academic performance (Ferriz-Valero et al., 2020, p.1).

Gamification has three main components including high-choice, low-risk in a structured setting (Osheim, 2013). The high-choice component aligns with progressive education as Dewey has frequently stated the necessity for choice in the classroom for students. The low-risk element is important for students and educators to grasp so that the games can be participated in freely, without fear of failure or significant loss. The structured environment is easily achieved in a conventional school classroom making gamification within progressive education both accessible and practical for educators.

One of the main appeals of integrating gaming elements for progressive educators is to produce meaningful learning experiences for students. A student perceives meaningfulness in the significance and/or relevance of the task (Osheim, 2013; Ryan et al., 2018). Consequently, gamification creates more importance for educational tasks by creating a simulation with high-choice, lowrisk, games where mastery was possible. Researchers discovered a "mastery climate positively predicted intrinsic motivation, enjoyment and concentration in PE" (Erturan Ilker \& Asci, 2019, p.381).

An example of digital games in physical education may include Pokémon go, Zombies Run, Geocaching and Superhero workout and can be accessed on many types of hand-held screens. Low tech alternatives include physical movement related games such as tag, red rover, eye-spy, soccer, Simon says and capture the flag. Studies have shown performance and student engagement to significantly increase (Kwak, 2017), as "teachers engage students in a lesson by activating their prior learning and experiences, clarifying the purpose for learning, and making connections to contexts that will help them see the relevance and the usefulness of what they are learning" (Ontario Ministry of Education, 2019, p.55). 
Games "embody some of the ideas about learning popularized by one of the giants of progressive education, John Dewey" (Waddington, 2015, p. 3). Certain kinds of video games engage students in simulated worlds that pose the kinds of experiential, structured problems Dewey endorses (Waddington, 2015). The lack of technology available historically was the main issue Deweyan educators ran into while trying to assert his idea of having students understand social systems by educating through occupations. It was much more difficult than it is now to accomplish progressive naturalism with the aid of modern technology (Ryan et al., 2018; Waddington, 2015). Gamification can reproduce alternate (virtual) realities and social systems previously unattainable and gamification in Physical Education encourages students through task-oriented flexible physical activity embedded in competition and personal fitness goals (Mushkin, 2016). These new possibilities lead to enhanced understanding and questioning of educational information. Progressive educators are given a tool in which to allow students choice and to test them in a low-risk structured game to extend their learning. Even though these modern technologies were not available to Dewey and other progressive educators in the past, it is at the disposal of today's teachers, and it should be used sensibly to create meaningful educational experiences for students (Waddington, 2015).

\subsection{Conflict}

In Canada a return to improving proficiency on standardized tests has unseated Dewey's theories in classrooms, as performance measurement and test scores are prioritized aims (Theobald, 2009). Education today is not progressive education according to Dewey, who viewed traditional settings as unfit developmentally (Theobald, 2009). Progressive education needs to be concerned with students in their present phase of development, not the future. The education system being primarily concerned with test scores driving performance in key areas, is a regression to a dated system that better supports traditional classroom settings (Williams, 2017). Dewey was fundamentally against the practice of overwhelming students with academic content that was not relevant to their lives at their current stage. He argued that by doing so it was to teach unethically (Williams, 2017). This current trend in education is a point of conflict and tension for progressive educators today.

Most "teachers begin teaching a class with only very limited understandings of what students in that class already know and can do" (Masters, 2013 , p. 15). However, "in an ideal world, the teacher would have precise and current knowledge of each student's starting points and also of what assistance each student requires to move to the next level" (Fullan et al., 2006, p. 34). Educators are preoccupied today with deep curricular content that need be 
covered in short periods of time and still have students do well on provincial tests. Unfortunately, in 2021 there remains a strong focus on increasing academic achievement through the use of a test content driven curriculum (teach to the test) in today's classrooms which makes examples of progressive education in classrooms less common than it used to be, as progressive education requires time to explore, play and experience authentic problems.

\subsubsection{Additional sources}

Some believe Progressive education contradicts itself with a childcentered approach to learning and self-discovery where ultimate choice and deviation from the norm is replaced with educational direction in the form of curriculum mandated by the government with the objective being; produce the best members of society (Bowers, 1967). Bowers believes,

in determining the greatest good for society and in using the school to achieve it, the educationist cannot at the same time encourage the individual's capacity for self-direction. For the educationist can control the direction of social change only as long as he controls the mind and life of the student. (p. 471)

This is the prime issue involving progressive education today, how does one employ progressive education without using it as a political tool for social reform? Well, the answer is quite simple; apply the provincial government curricula in a manner that stimulates progressivism. For instance, Ontario educators are encouraged by the new 2019 Health and Physical Education curricula to be progressive via instruction guidance and are told:

this experiential and student-centred approach is particularly important in health and physical education because it allows the teacher to respond to a range of experience, backgrounds, and abilities in physical activity settings and to respond to a range of needs and experiences when addressing healthy living topics and concepts. (p.33)

Somehow in the past progressive schooling movement was linked to elitism. Progressive advocates and those parents who opted to send their children to more progressive schools were often only able to because of their financial means. Towards the end of the $20^{\text {th }}$ century this trend dissipated (Semel et al., 2016). Although, this is clearly not what Dewey intended when he established his educational philosophy oriented around the principles of structured classroom, child-centered, liberal and free schools. For most of the $20^{\text {th }}$ century, these schools attracted a mostly white, upper middle-class group of students. Hence, the progressive schooling has remained with the connotation of school for the "elites" to this day (Semel et al., 2016, p. 378). 
Along similar lines, critics have argued progressive education to be more harmful than just an idealized elitist philosophy, but a romanticized one. Evers (1998) traces many of the problems associated with progressive education to its origins. He does not credit Dewey with full responsibility of founding most of the philosophy's ideas. Instead, he argues the Romantic era is largely responsible for the outlook Dewey and other progressives had towards education, children, and society as a whole (Evers, 1998). The Romantics saw life and learning as happening naturally, children are comparable to flowering plants and if they are nurtured and cared for properly, they will grow. Evers (1998) points to Rousseau and Emerson for inspiring much of Dewey's philosophy of the child as a natural learner full of curiosity and imagination. Therefore, textbooks, structure, and irrelevant information that does not align with the student interest impairs the learning more than it empowers. Evers narrows progressive education down to five tenets. He argues these five principles serve as evidence for us to not use progressive education as a model for schools today.

All learning in school is to come through playing, Children's social and emotional development and psychological attitudes (self-concept, selfesteem, how well the child works with others) are to be given an overriding importance, A high-school-as-supermarket curriculum, an approach in which core subjects are crowded out, should be adopted. Drudgery and hard work on the way to mastering a subject should be abolished, and Competition among students should be eliminated. (Evers, 1998, p. 5)

Evers admits that even ardent traditionalists in education should not ignore progressive ideas altogether. But states he cannot support an educational philosophy that prioritizes the process of learning over product from learning.

\subsection{The Future: Endpoint or Beginning?}

There is no shortage of opposition to the progressive education movement, and it is important to analyze resistance to better understand Dewey's philosophy and its opposition. Many of the critics overly simplify Dewey's concepts and exaggerate statements to create an image of progressive education as a student-run classroom where the teacher acts as observer and inquirer. This is untrue. Nevertheless, advocates for progressive education are yielding positive results in their classrooms today, even with an intensified effort by governments to standardize curriculum testing and increase system accountability.

Social scientists at the University of Chicago found that there is a strong relationship between social trust and the effect on quality of teaching for academic performance. The study found that strong relationships between 
teachers and students create an increase in scholastic performance (Waddington, 2015). Dewey's concern with citizenship in the face of an ever-changing industrial society is similar to the changes happening at present via technology. Like industrialism in Dewey's time, technology in contemporary times is a major driver behind political and economic change (Waddington, 2015, p.7). A diverse and daunting information system that is rapidly changing with technology gives way to a new set of global issues. Intellectual problems for young learners will expose them to global warming, nuclear waste, resource depletion and food and water challenges. These real-world authentic problems present a myriad of challenges and correspond with a variety of potential solutions. Thus, to make learning more authentic teachers need to address these issues in class with meaningful inquiry-based lessons and draw conclusions through social discourse. This task seems to be made easier within the 2019 Ontario Health \& Physical Education curricular document that includes Figure one with a focus on inquiry.

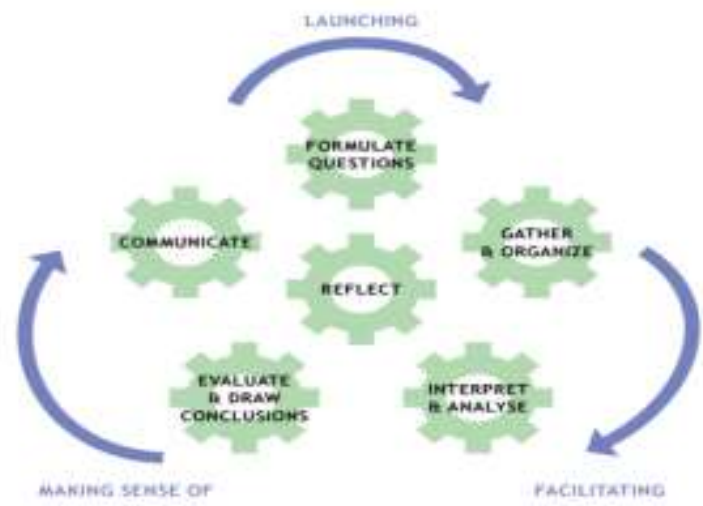

Note. (OPHE, 2015, p. 8).

Figure 1: Inquiry Framework for Health \& Physical Education-Six components of Inquiry based Learning

Even though education is shifting from Deweyan progressive education values, it will be forced to incorporate more and more progressive ideas as the school system becomes modernized. This is due to the job market becoming increasingly technologized and automated, placing an increased demand on workers with a well-rounded understanding of Health, Wellness and Physical Education in this fast-paced online landscape operated by people. The amount of educational technology becoming accessible to educational institutions each year 
paves the way for gamification and classrooms taking on more game-based curriculum to supplement the learning and engage the digital youth. Progressive education may see a resurgence coinciding with the tech boom. Project based learning and inquiry-based learning is more convenient for teachers with tech projects online. Even if standardized testing and common core standards remain, the addition of PBL and gamification contributes to a more progressive and modern education system.

There are many examples of specific progressive programs that actively practice Dewey's philosophy. Philosophy for Children (P4C) is a type of instructional method that is designed to incite critical thinking skills and cause students to question within their own communities. Through this program, students are exposed to debates at a young age and shown it is acceptable to disagree and to respect alternate ways of thinking about a particular topic. The skill of critical thinking, listening, and debating is something Dewey would desire in his ideal social learning classroom. Teachers are more than instructing with a progressive program like $\mathrm{P} 4 \mathrm{C}$, they are facilitators of meaningful discussion for their learners. Much like Dewey's belief in schools developing moral and social development in the youth, P4C is created to cultivate, "mutual co-operation, trust, tolerance, fair mindedness and a heightened degree of sensitivity to their peers" (Williams, 2017, p. 100). Programs such as this are modern adaptions of progressive child-centred learning in contemporary times.

Another example is Place-Based Education or PEEC. It is inspired by the progressive concept that education should "seek to extend learning beyond the walls of the school". PEEC achieves this by having students engage in outdoor education activities to interact with their natural environment and urban communities to become socially aware citizens (Williams, 2017, p. 99). Progressive programs like this show students that learning extends beyond the physical classroom and that they can derive learning outside of the traditional classroom model.

The Responsive Classroom is an initiative that involves Dewey's social learning theory of establishing a strong, trusting community where learning can happen organically through social means. The concept asserts that high-quality education is dependent on a protected and positive learning place. The main practices of a Responsive Classroom establish routines of respect, the Morning Meeting method, Energizers, and Closing Circles. All of which aim to support students socially and to reinforce the safety of the learning space for all. Whilst, creating meaningful learning experiences in their classroom community (Williams, 2017, p. 94). 
Furthermore, progressive education has not completely taken off the pedagogical landscape in North America in modern times. However, it is alive and well and has adapted itself to the innovation and creativity spurred on by technology and incorporated it into its philosophy. Progressive educators are still able to teach with Deweyan philosophical principles, but they are now doing so in a more digital framework. As a result, educators and their students work towards learning that enables them to become more informed democratic global citizens of the technologized $21^{\text {st }}$ century.

\section{References}

Barrows, H.S., \& Tamblyn, R.M. (1976). An evaluation of problem-based learning in small groups utilizing a simulated patient. Journal of Medical Education 51(1), 52-54.

Barrows, H.S., \& Tamblyn, R.M. (1980). Problem based learning: An approach to medical education. Springer Verlag.

Bowen, G. A. (2009). Document analysis as a qualitative research method. Qualitative Research Journal, 9(2), 27-40. doi:10.3316/QRJ0902027

Bowers, C.A. (1967). The ideologies of progressive education. History of Education Quarterly, 7(4), 452-473. doi:10.2307/367463

Canada, E. A. (2019, March 25). Government of Canada. Retrieved from https://www.canada.ca/en/employment-social development/programs/seniors-action- report.html

Cremin, L. (1959). John Dewey and the progressive-education movement, 19151952. The School Review, 67(2), 160-173.

Davies, S. (2002). The paradox of progressive education: A frame analysis. Sociology of Education, 75(4), 269-286. doi:10.2307/3090279

Demirel, M., \& Dağyar, M. (2016). Effects of problem-based learning on attitude: A meta-analysis. Eurasia Journal of Mathematics, Science and Technology Education, 12(8), 2115-2137. doi:10.12973/eurasia.2016.1293a

Erturan İlker, G., \& Aş̧̧i, H. (2019). The role of teacher's feedback in physical education: Motivational climate as mediator. Hacettepe University Journal of Education, 34(2), 372-386. doi:10.16986/HUJE.2018043404 
Evers, W. M. (1998). How progressive education gets it wrong. Hoover Digest, 4.

Ferriz-Valero, A., Østerlie, O., Martinez, G. S., \& García-Jaén, M. (2020). Gamification in Physical Education: Evaluation of impact on motivation and academic performance within higher education. International Journal of Environmental Research and Public Health. 17, 4465.

Fullan, M., Hill, P., \& Crevola, C. (2006). Breakthrough. Corwin.

Hsieh, H.-F., \& Shannon, S. E. (2005). Three approaches to qualitative content analysis. Qualitative Health Research, 15(9), 1277-1288. https://doi.org/10.1177/1049732305276687

Jonassen, D. H., \& Hung, W. (2008). All problems are not equal: Implications for problem-based learning. Interdisciplinary Journal of Problem-Based Learning, 2(2). https://doi.org/10.7771/1541-5015.1080

Kindermann, K. (2020). Summative content analysis as a core method to reconstruct subjective theories using structure-formation-techniques. Forum Qualitative Sozialforschung / Forum: Qualitative Social Research, 21(1). doi:http://dx.doi.org/10.17169/fqs-21.1.3324

Korpi, H., Peltokallio, L., \& Piirainen, A. (2019). Problem-based learning in professional studies from the physiotherapy students' perspective. Interdisciplinary Journal of Problem- Based Learning, 13(1). https://doi.org/10.7771/1541-5015.1732

Kwak, J.Y. (2017). Exploring the use of mathematics apps in the elementary school classroom. https://www.semanticscholar.org/paper/Exploring-theuse-of-mathematics-apps-in-the-school

Labaree, D. (2005). Progressivism, schools and schools of education: An American romance. Paedagogica Historica, 41(1),275-288. doi:10.1080/0030923042000335583

Little, T. (2013). $21^{\text {st }}$ century learning and progressive education: An intersection. International Journal of Progressive Education, 9(1), 8496. 
Masters, J. N. (2013). Reforming education assessment: imperatives, principles and challenges. Australian Council for Educational Research. Camberwell, Victoria: ACER Press.

Mushkin, J. (2016, May 4). Is gamification the next step in physical education? https://www.edutopia.org/discussion/gamification-next-step-physical$\underline{\text { education }}$

Noddings, N. (1995). Philosophy of Education. Westview.

Ontario Ministry of Education. (2019). The Ontario Curriculum Grades 1-8: Health and Physical Education. Retreived from http://www.edu.gov.on.ca/eng/curriculum/elementary/2019-healthphysical-education-grades-1 to $8 . p d f$

Osheim, D. E. (Spring 2013). This could be a game!” Defining Gamification for the Classroom. San Jose State University, 1-117. Retreived from https://doi.org/10.31979/etd.e6tp-u2vw

Reese, W. (2001). The origins of progressive education. History of Education Quarterly, 41(1), 1-24. http://www.jstor.org/stable/369477

Ryan, T. G. (2008a). Philosophical orientation in pre-service. The Journal of Educational Thought, 42(3), 247-260.

Ryan, T. G. (2008b). Philosophical homogeneity in pre-service education: A longitudinal Survey. Issues in Educational Research, 18(1), 73-89. .

Ryan, T. G., Presley, A., \& Sinay, E. (2018). Edification of education: An illumination of best practices, effectiveness and improvement. Journal of Educational Thought, 51(1), 7-34.

Salen, K., \& Zimmerman., E. (2004). Rules of play: Game design fundamentals. MIT Press, Cambridge, MA.

Semel, S. F., Sadovnik, A. R., \& Coughlan, R. W. (2016). Progressive education: Lesson from the past and present. Faculty Works: Education. 81. https://digitalcommons.molloy.edu/edu_fac/81

Schreier, M. (2012). Qualitative Content Analysis in Practice. Sage. 
Theobald, P. (2009). Education Now: How Re-thinking America's Past Can Change Its Future. Colorado: Paradigm.

Waddington, D. (2015). Dewey and video games: From education through occupations to education through simulations. Educational Theory, 65, 1-20 https://doi.org/10.1111/edth.12092

Western Australia Department of Education. (2021). What is STEM? Retreived from https://www.education.wa.edu.au/what-is-stem

Williams, M. K. (2017). John Dewey in the $21^{\text {st }}$ Century. Journal of Inquiry and Action in Education, 9(1), 91-102. Retreived from https://paperity.org/p/85018588/john-dewey-in-the-21st-century

Woods, J.G. (2012). Using cognitive conflict to promote the use of dialectical learning for strategic decision-makers, The Learning Organization, 19(2), 134-147.

\section{Citation of this Article:}

Ryan, D. T., \& Ryan, T. G. (2021). Deweyan Progressive Education within Ontario Health and Physical Education. International Journal of Innovation in Teaching and Learning (IJITL), 7(1), 20-38 